Cómo citar este artículo en Chicago: Álvarez Lobato, Carmen. "La escritura femenina en La travesía, de Luisa Valenzuela: entre los pliegues del yo autobiográfico”. Escritos 30, no. 64 (2022): 77-88. doi: http://doi.org/10.18566/escr.v30n64.a05

Fecha de recepción: 29.07 .2021

Fecha de aceptación: 13.12 .2021

\title{
La escritura femenina en La travesía, de Luisa Valenzuela: entre los pliegues del yo autobiográfico
}

\author{
Feminine writing in La travesía, by Luisa Valenzuela: between the folds \\ of the autobiographical self
}

\author{
Daniela Álvarez Yepes ${ }^{1}$
}

\begin{abstract}
RESUMEN
En este artículo se analizan las estrategias autofigurativas de La travesía de Luisa Valenzuela en términos de las narrativas del yo, la dictadura argentina y el feminismo, encontrándose una correspondencia entre la desautorización de la voz y la estructura del relato autobiográfico y el retrato de la experiencia de la violencia del régimen militar y de género. Inicialmente, se sitúa a la novela en el auge de las narrativas del yo que, con recursos literarios que se separan de los escritos autobiográficos más conservadores, denuncian la imposibilidad de entender al sujeto como unívoco, a la vez que fundan diferentes aproximaciones al recuento de la experiencia. Dicha localización permite explorar los experimentos formales que Valenzuela lleva a cabo en torno al ejercicio autobiográfico y que ponen de relieve la crisis de la construcción de la memoria y la exposición de la subjetividad contemporánea. Además, se demuestra cómo tales estrategias sirven de vehículo a la reflexión sobre el feminismo y la dictadura que permean la totalidad de su obra. Para esto, se acude a la noción de escritura femenina de Valenzuela, la cual antepone la multiplicidad de perspectivas a la univocidad de la voz autobiográfica, lo ambiguo a lo preciso, y lo colectivo a lo autoritario. La travesía es, entonces, leída como parte de las obras que acuden a la narración de la propia experiencia en un marco del recuento de la memoria colectiva, con juegos narrativos que señalan la futilidad deíctica del yo y la dificultad de relatar el tiempo pasado, sin, por ello, abandonar el llamado a su reconstrucción como garantía de no repetición.
\end{abstract}

Palabras clave: Autobiografía; Autoficción; Autofiguración; Luisa Valenzuela; Novela de dictadura; Escritura femenina; Narrativas del yo.

1 Estudiante de Maestría en Estudios Culturales de la Universidad de Freiburg, Alemania. Profesional en Estudios Literarios. Correo: daniela1224@gmail.com. 


\begin{abstract}
This article analyzes the autofigurative strategies of La travesía by Luisa Valenzuela in terms of the narratives of the self, the Argentine dictatorship and feminism. A correspondence is found between the disavowal of the voice, the structure of the autobiographical account and the portrait of the experience of the violence of the military regime and of gender. Initially, the novel is situated at the height of the narratives of the self that, with literary resources that are separated from the most conservative autobiographical writings, denounce the impossibility of understanding the subject as univocal, while founding different approaches to the retelling of the experience. This location allows exploring the formal experiments that Valenzuela carries out around the autobiographical exercise and that highlight the crisis of the construction of memory and the exposure of contemporary subjectivity. In addition, it is shown how such strategies serve as a vehicle for reflection on feminism and dictatorship that permeate all of her work. For this, Valenzuela's notion of feminine writing is used, which puts the multiplicity of perspectives before the univocity of the autobiographical voice, the ambiguous before the precise, and the collective before the authoritarian. La travesía is, then, read as part of the works that come to the narration of the experience itself in a framework of the retelling of collective memory, with narrative games that point out the deictic futility of the self and the difficulty of recounting past time, without, therefore, abandoning the call for its reconstruction as a guarantee of non-repetition.
\end{abstract}

Keywords: Autobiography; Autofiction; Autofiguration; Luisa Valenzuela; Dictatorship Novel; Feminine Writing; Narratives of the Self.

$\mathrm{D}$ esde que en el siglo XX se declaró la muerte de la poesía, los escritores se han dedicado a sortear el enmudecimiento traído por la guerra. La literatura latinoamericana, compuesta de un monumental número de obras alrededor de las dictaduras, los exilios y las desapariciones, representa un caso paradigmático del esfuerzo por narrar el horror. Esa apuesta ha significado una explosión de las formas y los estilos narrativos. En particular, en la literatura argentina que precedió a 1973, esto significó pensar un lenguaje más plástico y maleable, que permitiera acercarse a una realidad que se batía entre límites absurdos. ${ }^{2}$

Si bien la tendencia a la experimentación es una de las características estéticas atribuidas al boom latinoamericano, buena parte de la literatura de fin de siglo, en ocasiones, agrupada bajo la etiqueta de post-boom, se desliga de esta al enlazar los juegos formales y narrativos con una orientación hacia la realidad sociopolítica. ${ }^{3}$ Es el caso de la escritora argentina Luisa Valenzuela, cuya obra ha sido celebrada por la crítica debido a la combinación de estilos asincrónicos y heterogéneos, el uso de la parodia, la fragmentación de las voces y la desjerarquización de los discursos en el tratamiento de la violencia estatal y de género que ha dibujado como dos caras de la misma moneda. ${ }^{4}$

2 Cristina Piña, "La narrativa argentina de los años setenta y ochenta", Cuadernos Hispanoamericanos, no. 517-519 (1993): 124.

3 Philip Swanson, “The Post-Boom Novel", en The Cambridge Companion to the Latin American Novel, ed. por Efraín Kristal (Cambridge: Cambridge University Press, 2005), 83.

4 Alyce Cook, "Luisa Valenzuela’s La travesía: A Search for Order", en Modernisms and Modernities: Studies in Honor of Donald L. Shaw, ed. por Susan Carvalho (Newark: Juan de la Cuesta, 2006), 321-331; Gwendolyn Díaz, "Una odisea hacia el caos: 'La travesía' de Luisa Valenzuela", Biblioteca Virtual Miguel de Cervantes, http://www.cervantesvirtual. com/obra/una-odisea-hacia-el-caos-la-travesia-de-luisa-valenzuela-931424/; Jaime P. Gómez, "La representación de la dictadura en la narrativa de Marta Traba, Isabel Allende, DiamelaEltit y Luisa Valenzuela", Confluencias 12, no. 2 (1997): 89-99; Susana Ynés González Sawczuk, "A dos tiempos: Narrativas de autoficción en La travesía de Luisa Valenzuela", en Luisa Valenzuela: Perspectivas críticas. Ensayos inéditos, coord.. por Pol Popovic-Karic y Fidel Chávez (Monterrey: Instituto Tecnológico y de Estudios Superiores de Monterrey, 2013), 39-62; Nelly Martínez, "Luisa 
La obra de Valenzuela está conformada, principalmente, por colecciones de relatos y novelas en que el poder aparece materializado en diferentes avatares, entre esos, el Estado, el falo y el lenguaje, que han correspondido a las diversas perspectivas con que los críticos han abordado su narrativa. En el caso de sus obras más comentadas, Simetrías (1993) y Cambio de armas (1982), se ha señalado que su tratamiento literario logra entretejer "el discurso privado [con] el público, lo erótico con lo político, y el sufrimiento individual concreto con la retórica abstracta del autoritarismo de la llamada 'guerra sucia”, para demostrar que tales sincronías no son ajenas a la dictadura, sino sus propias armas. ${ }^{5}$ Ese juego de equivalencias entre los modos de represión construye el núcleo de, incluso, sus obras más experimentales tanto formal como temáticamente, en las que los engranajes de sintaxis erráticas, sistemas gramaticales desmontados y visiones caleidoscópicas parecieran no remitir a la realidad política argentina. Sin embargo, es ese enmascaramiento de la realidad material, como si de un secreto se tratara, lo que destaca su obra y lo que ha llevado a críticos como Jaime P. Gómez a preferirla frente a las llamadas novelas de dictador, enfocadas en la figura magnética del tirano, por mover al centro de la representación al sujeto y lo colectivo, así como los efectos devastadores del régimen militar. ${ }^{6}$ La narrativa de Valenzuela arremete contra esos personajes gigantescos y los desplaza a entornos fragmentados, plurales y dialógicos, donde su discurso e imagen son confrontados.

En ese particular universo narrativo, aparece La travesía, novela publicada en 2001 por Norma y recientemente reeditada por Arte y Literatura en 2017, que ha sido leída por la crítica en clave de feminismo, con énfasis en el cuerpo y el deseo: dos de los principales ejes temáticos de la obra. La travesía narra los esfuerzos de una mujer por localizarse en su memoria y en su propio deseo; un viaje, como se intuye desde el título, en el que sale a su encuentro.

Formalmente, La travesía se construye como un experimento del género autobiográfico desde el que se fabrican reflexiones en torno a la memoria, a la posibilidad de narración de la experiencia y a la autoridad deíctica del yo que, aun volviendo sobre el recuento de la violencia dictatorial, si bien de manera menos evidente, no ha sido cabalmente analizado por la crítica. La novela funciona así como un escenario donde Valenzuela extiende una narración heterogénea, que no termina de decidirse entre la ficción, la autobiografía y el ensayo, y que es a la vez punto de encuentro de sus reflexiones sobre el poder, el deseo y el cuerpo y la preocupación por la narración de la propia experiencia. De esta manera, el lector acude a una obra en línea con las propuestas estéticas y formales de la época -ya se entreveía la popularidad que tendría la autoficción y otras narrativas del yo, así como el despliegue estilístico de la llamada literatura posmoderna-, que presenta, aunque de manera subrepticia, una aguda denuncia de la estructura patriarcal y el régimen militar argentino; todo ello atravesado por la pregunta de cómo volver sobre la memoria y la fiabilidad de su recuento.

Valenzuela’s 'La travesía': The Vagina Monologues and the Experience of Wholeness”, Letras Femeninas 30, no. 1 (2004): 92-105; María Teresa Medeiros-Lichem, "Nuevos derroteros del lenguaje: La travesía de la escritura de Luisa Valenzuela”, Biblioteca Virtual Miguel de Cervantes, http://www.cervantesvirtual.com/obra/nuevos-derroteros-del-lenguaje-latravesia-de-la-escritura-de-luisa-valenzuela-931752/; Joy Logan, "Southern Discomfort in Argentina: Postmodernism, Feminism, and Luisa Valenzuela's 'Simetrías”, Latin American Literary Review 24, no. 48 (1996): 5-18.

5 María Teresa Medeiros-Lichem, "Luisa Valenzuela: 'La mala palabra", en La voz femenina en la narrativa latinoamericana: Una relectura crítica (Santiago de Chile: Cuarto Propio, 2006), 209.

6 Gómez, "La representación de la dictadura en la narrativa de Marta Traba, Isabel Allende, Diamela Eltit y Luisa Valenzuela". 
Ese ejercicio de rememoración que moviliza la trama de la historia concuerda con la monumental tarea de recordar que se impuso a la nación argentina después de la dictadura y que coincide con un momento en que la inmersión en la intimidad de la subjetividad crece como un signo de la época y en que la alta publicación de obras literarias, construidas sobre pretensiones autobiográficas o desfiguraciones de estas, da cuenta de una expectativa cada vez mayor de acceder al espacio privado del otro o exponer el propio. ${ }^{7}$ En este sentido, resulta interesante abordar La travesía frente a las narrativas del yo, la construcción de la memoria y el rol de la subjetividad en el espacio público y privado, entre el relato individual y colectivo, desde un análisis de los mecanismos narrativos y formales que amplíen los límites de una lectura meramente temática.

La travesía se construye en dos partes y una introducción, llamada botadura, inauguradas con un paratexto en que se le define como una autobiografía apócrifa. En este, se anuncia al lector que la protagonista es inventada, pero los demás personajes son reales, completa o parcialmente, según lo requiere el hilo de la historia. Además, a la protagonista se le ha prestado el cuerpo y "ciertos movimientos del alma" de la autora, ${ }^{8}$ aunque no por ello las circunstancias; toda semejanza con la realidad, se advierte, es "absolutamente voluntaria". La historia de la protagonista transcurre sobre el recuerdo de unas cartas eróticas que escribió hace más de dos décadas, por lo demás nunca mostradas al lector, y que amenazan con perturbar la vida que ha construido lejos de Argentina.

Esa nota aclaratoria enfrenta al lector a una primera aporía: la obra es autobiográfica, pero se le considera apócrifa; narra la historia de una mujer que no comparte con la autora los hechos de su vida y que, como encontrará al asomarse a la botadura, ni siquiera lo hace en primera persona.

En general, lo apócrifo suele remitir a textos excluidos de las escrituras sagradas del cristianismo que también narran la vida de Jesús. La distinción entre los textos aceptados y los apócrifos se da desde una idea de canon que prescribe las características que han de tener las escrituras sagradas. La selección de lo canónico con respecto a lo apócrifo se dirime así en dos sentidos: la autoría y la estructura. En el caso de lo estructural, lo apócrifo remite a aquello que no da cuenta ni del estilo ni de la temática de lo esperado para este tipo de narración. Por su parte, el problema de la autoría supone que alguien más aprueba la idoneidad del otro para contar los hechos. De esta forma, lo apócrifo alude a lo falso desde lo erróneo y lo ilegítimo.

En cuanto a la autobiografía apócrifa que plantea Valenzuela, el adjetivo da cuenta de una estructura que no se acomoda a lo que se espera de los textos autobiográficos. Si bien los géneros narrativos del yo se han abierto formalmente, los estudios de la autobiografía distinguen ciertos rasgos convencionales como la convergencia entre el personaje principal, que con frecuencia también es narrador, con la persona o nombre del autor, la narración en primera persona y en pretérito, entre otros. ${ }^{10}$ En el sentido de $\mathrm{La}$

7 Leonor Arfuch, El espacio biográfico: Dilemas de la subjetividad contemporánea (Buenos Aires: Fondo de Cultura Económica, 2002); Nora Catelli, En la era de la intimidad: Seguida de El espacio autobiográfico (Buenos Aires: Beatriz Viterbo, 2007); Beatriz Sarlo, Tiempo pasado: Cultura de la memoria y giro subjetivo. Una discusión (Buenos Aires: Siglo XXI, 2011).

8 Luisa Valenzuela, La travesía (Alfaguara, 2002), 12.

9 Valenzuela, La travesía, 12.

10 Jesús Camarero, Autobiografía: Escritura y existencia (Barcelona: Anthropos, 2011), 27; Philippe Lejeune, El pacto autobiográfico y otros estudios (Madrid: Megazul Endymion, 1994), 125. 
travesía, el epíteto que le acompaña trae a cuenta las crisis que en el siglo XX sufrieron la novela, el sujeto y, con este, el autor. ${ }^{11}$ La denominada muerte del sujeto logró fragmentar las estructuras clásicas de los géneros biográficos al cuestionar nociones como identidad, experiencia y narración, fundamentales en el desarrollo de estas formas narrativas. Autobiografías escritas en tercera o segunda persona, disparidad en los nombres del autor y el personaje, cronologías desordenadas, entre otros recursos narrativos, han complicado la distinción pretendida desde la teoría entre lo ficcional y lo biográfico o confesional, y descubierto nuevos puntos nodales en la reflexión sobre la escritura del yo.

Lo apócrifo se lee, además, como un artilugio para el engaño, que remite a una intención autorial. En la novela, nombrarse de esta manera pone de relieve la complejidad del pacto entre autor y lector, devela al último la falsedad de lo que se retrata y produce un efecto de lectura que dinamita la pretensión autofigurativa del texto, en tanto autobiografía, a la vez que lo funda. El paratexto abre, entonces, un horizonte de expectativas en el lector del encuentro con la obra que cambia conforme el objeto literario se denomina testimonio, entrevista u autobiografía. En La travesía, el paratexto funciona como una invitación a perderse en los juegos literarios de Valenzuela, en el que este es tan solo un detalle en un complejo armazón narrativo. Asimismo, esa suerte de advertencia de la maleabilidad de la narración en primera persona deja entrever la reflexión alrededor de la memoria, el sujeto y la posibilidad de narrar que sostiene toda la novela: no hay manera de enfrentar el hiato de lo inefable desde el soliloquio de un sujeto unívoco. Ante ese "quiebre irreparable de la narración", que Nelly Richard adjudica a las dictaduras latinoamericanas, ${ }^{12}$ Valenzuela elige narrar los fragmentos desde una escritura que ha denominado femenina, una que se "esconde entre los pliegues de aquello que se resiste a ser dicho" ${ }^{13}$ y que configura una búsqueda por subvertir los discursos de poder.

En La travesía, la escritura femenina moldea todas las dimensiones narrativas de lo que pretende ser una autobiografía. Contrario a lo esperado para un obra confesional, la novela sucede casi completamente bajo el lente de una narradora heterodiegética que sigue la historia de una antropóloga argentina radicada en Nueva York en las últimas dos décadas del siglo XX. El pretendido yo autobiográfico se ve diluido en la figura de otra que, además, se nombra hasta el último capítulo como ella, anclada a un sin lugar de la enunciación que caracteriza a la tercera persona como poseedora de una ausencia. ${ }^{14}$

El secreto nominal de la protagonista contrasta con los demás personajes, de los que se sabe por el paratexto que fueron tomados, al menos en parte, de la realidad de Valenzuela. Mientras estos son nombrados, esta se queda en una mención pronominal. El signo ella aparece en el lenguaje como vacío. Su existencia depende de quien se enuncia como yo, quien narra en este caso y que ha decidido no adherir su persona a un nombre, sino designarla con una palabra que por su naturaleza sirve para referirse a cualquiera. Siguiendo a Paul Ricœur, la función del nombre propio está en singularizar una entidad no repetible, relacionada con la construcción de la identidad del individuo y su posicionamiento frente a la

11 Peter Bürger y Christa Bürger, La desaparición del sujeto: Una historia de la subjetividad de Montaigne a Blanchot (Madrid: Akal, 2001), 13.

12 Nelly Richard, Fracturas de la memoria (Buenos Aires: Siglo XXI, 2004), 171.

13 María Teresa Medeiros-Lichem, "El sujeto nómada y la exploración de la memoria en 'La travesía de Luisa Valenzuela”, Biblioteca Virtual Miguel de Cervantes, http://www.cervantesvirtual.com/obra/el-sujeto-nomada-y-la-exploracionde-la-memoria-en-la-travesia-de-luisa-valenzuela-931776/.

14 Émile Benveniste, Problemas de lingüística general (México: Siglo XXI, 1979), 164. 
alteridad. ${ }^{15}$ La protagonista se presenta, entonces, escindida de su identidad, al menos parcialmente. En la botadura, se dice que es antropóloga y argentina; a lo largo de la novela a esos rasgos se le añadirán que trabaja en una prestigiosa universidad norteamericana, escribe, tiene un cabello negro rizado, apariencia gitana y que abandonó Buenos Aires a finales de la década de 1970. Todas estas características llenan, al menos en apariencia, el desocupado pronombre ella con el cuerpo y las vivencias de Luisa Valenzuela; de esta manera, la novela se resiste hasta el final al calificativo de ficción que amenaza con desplazar el de autobiografía apócrifa, asegurando la inmersión del lector en su juego literario.

En los estudios más convencionales de los escritos autobiográficos, es la coincidencia entre el nombre del protagonista y la firma del autor lo que sella el pacto autobiográfico: esa suerte de invitación a conocerle que hace el escritor y que para algunos teóricos inauguró Jean-Jacques Rousseau cuando escribió en Las confesiones: "Quiero mostrar a mis semejantes un hombre con toda la verdad de la naturaleza, y ese hombre soy yo". ${ }^{16}$ El efecto de verdad asociado a la firma tiene una larga trayectoria que escapa a los límites de las escrituras autobiográficas. Como menciona Laura Scarano, acudiendo a Raymond Williams, la palabra autor designa un sentido de origen, integrado de fuerte manera con las palabras autoridad o propiedad intelectual. ${ }^{17}$ Es el autor otra manifestación del sujeto moderno, racional y centrado, que creía dibujar su realidad sin velo alguno cuando escribía yo y frente al que Valenzuela antepone su escritura femenina. En La travesía, el autor no es marca que define el texto, sino su secreto.

Esa afición por lo que está oculto, señalada por Valenzuela como fundadora de toda su narrativa, ha determinado también su visión de la literatura en general. En Escritura y secreto, la autora presenta el secreto como el inasible objeto de deseo de la literatura que la impulsa hacia los límites de lo inefable. ${ }^{18}$ Pero no es solo al escritor a quien moviliza el secreto, también la lectura es un acto de desciframiento que busca poner lo oculto en presencia. ${ }^{19}$ En La travesía, la posibilidad de desentrañar el secreto que alimenta toda lectura se conjuga con la promesa del sujeto autobiográfico de descubrirse, que no han desmantelado del todo los críticos del género. Por el contrario, desde finales del siglo pasado, las narraciones del yo, impulsadas por la confianza en el potencial de la primera persona de reconstruir la experiencia, han crecido en popularidad. ${ }^{20}$ Para Beatriz Sarlo, ese giro hacia el relato de la subjetividad desmiente la visión fatalista de Walter Benjamin del empobrecimiento de la experiencia traído por la guerra que impediría la narración y de los análisis deconstructivistas de Paul de Man y Jacques Derrida que anunciaban la imposibilidad de acercarse al acontecimiento y, con ello, la de narrarlo. ${ }^{21}$ La sentencia de De Man de que la autobiografía sería indistinguible de la ficción en primera persona, terminando por hacerla desaparecer, se ha encontrado con la negativa de los lectores a dejar de leer las peripecias del yo en clave de autenticidad, incluso, cuando este aparece tras un velo. De hecho, no ha existido un mejor momento para el género autoficcional y otras formas experimentales de las narrativas del yo que, aun prescindiendo de la primera persona, prometen mostrar el mundo como no se concede hacerlo a la ficción.

15 Paul Ricoeur, Sí mismo como otro (Madrid: Siglo XXI, 2013), 3.

16 Jean-Jacques Rousseau, Las confesiones (Madrid: Edaf, 1980), 1.

17 Laura Scarano, Palabras en el cuerpo: Literatura y experiencia (Buenos Aires: Biblos, 2007), 94.

18 Luisa Valenzuela, Escritura y secreto (México: Ariel, 2002), 12.

19 Valenzuela, Escritura y secreto, 30.

20 Scarano, Palabras en el cuerpo, 85.

21 Beatriz Sarlo, Tiempo pasado: Cultura de la memoria y giro subjetivo. Una discusión (Buenos Aires: Siglo XXI, 2011 ), 39. 
En La travesía, es precisamente en la potencia de denominarse autobiografía, aunque apócrifa, en que la escritura femenina dinamita la jerarquía caprichosa del discurso hegemónico autobiográfico y desmonta el lenguaje patriarcal, desde el que el régimen militar y el sujeto moderno prometieron confesar su unívoca verdad. En este punto, vale la pena mencionar el análisis de Élise Couture-Grondin de la obra narrativa de la argentina, en el que señala que esa oposición de la escritura femenina a las formas de poder, materializadas en el régimen y en el lenguaje, pone de manifiesto la equivalencia de lo subversivo con lo femenino y la corrupción del cuerpo y lo militar con lo masculino, limpio y ordenado en el discurso de la dictadura. ${ }^{22}$

Esa correspondencia entre lo femenino y lo que amenaza al orden aparece en la novela movilizada por las cartas que la protagonista ha escrito dos décadas atrás a su exmarido secreto, Facundo; un profesor bastante mayor que ella, quien, siendo totalmente reticente a cumplir los deseos sexuales de la protagonista, decide enviarla al extranjero a cambio de la narración de desaforados encuentros sexuales con desconocidos. Lo atractivo de las cartas es que el contenido vivencial que se narra es totalmente ficcional: "F pretendió meterla de cuerpo entero en lo abyecto y ella logró meterse en esa otra forma de abyección que es la mentira. Una representación. Un simulacro". ${ }^{23}$ Los hechos son inventados por la protagonista, pero la narración se presenta a Facundo como auténtica.

El deseo sexual, en tanto volitivo y femenino, aparece doblemente negado por Facundo, metonimia tanto de la hegemonía patriarcal como del dominio dictatorial en Argentina. De ahí que la crítica coincida en señalar que la travesía de la protagonista es liberar su cuerpo del sometimiento de la sexualidad fálica. ${ }^{24}$ Asimismo, el conflicto que la mueve a amputar su memoria es producto de leer su deseo como censurable: "para contaminarse se bastaba sola, inventando a pedido de su secreto esposo historias cada vez más jugosamente envilecedoras, sin preguntarse por qué, sin siquiera entrar de lleno en su propio deseo. Sucia se sentiría entonces por imperativo del deseo ajeno. Sucia no por suciedad real sino por falta de discernimiento". 25 Para Díaz, ese negarse a recordar es común a todos los argentinos, quienes tuvieron que enfrentarse a la obcecada obediencia que el régimen impuso como base de su identidad. Sin embargo, así como la nación argentina hubo de aceptar la ineludible presencia del pasado, la protagonista es llevada a reconocer cuánto de su deseo hay en las cartas eróticas enviadas a F y cuánta de esa ficción la habita.

Ese enfrentamiento con la memoria no puede darse más que por medio de la escritura. En La travesía, la mujer escribe una nueva carta a Facundo, por la que "empieza a sospechar que quizá, sin proponérselo, sin poder confesárselo al mentirle a F quizá, quizá, quizá estaba diciendo alguna verdad profunda, incomprensiblemente propia." ${ }^{26}$ Esa consciencia de llegada a su propia escritura, la que pone en palabra su deseo, da cuenta de un punto de partida de la escritura femenina que "se traduce en la resistencia a aceptar códigos masculinos de la sexualidad y en el afán de recuperar el valor de la experiencia y la perspectiva de mujer". ${ }^{27}$

22 Élise Couture-Grondin, "La expresión del deseo en la literatura femenina como respuesta a la opresión dictatorial y patriarcal en la obra de Luisa Valenzuela" (tesis de maestría, Université de Montréal, 2011), 22.

23 Valenzuela, La travesía, 181.

24 Martínez, "Luisa Valenzuela’s 'La travesía”; Medeiros-Lichem, "El sujeto nómada y la exploración de la memoria en 'La travesía' de Luisa Valenzuela"; Selimović, "Sexing of the City".

25 Valenzuela, La travesía, 180.

26 Valenzuela, La travesía, 195.

27 Medeiros-Lichem, “El sujeto nómada y la exploración de la memoria en 'La travesía' de Luisa Valenzuela”, 4. 
Por otro lado, poder narrar lo que antes no podía ser nombrado desde la ficción, sin eliminar por ello la dimensión memorial, permite a Valenzuela introducir en la diégesis reflexiones en torno a lo ficcional y lo biográfico, lo auténtico y lo vivencial, articulándose en un segundo nivel con lo que la novela misma plantea frente a ello. Como una suerte de guiño al lector, la narradora califica la empresa epistolar de la protagonista de una autobiografía apócrifa:

Fue al puerto, por lo tanto, sin intención de levantar marinero alguno. Levantó ideas, inspiración que le dicen, y volvió hecha otra y de su boca salieron palabras nunca antes pronunciadas por ella ni-supuso- por mujer alguna de su estirpe, y casi sin darse cuenta empezó la saga de una autobiografía apócrifa que se iría transformando en un erotismo oral desaforado. ${ }^{28}$

El surgimiento del yo en la narración de hechos ficticios trae a cuenta la visión de Ricœur sobre la escritura de la propia experiencia. Para Ricœur, poder reconocerse como sí mismo requiere la narración de la experiencia, pasando de la identidad idem (lo superficialmente inalterado como el nombre propio) a la identidad ipse (una concepción coherente del yo). ${ }^{29}$ La transformación de lo idem a lo ipse demuestra que la ficción no "impide la ideación de una personalidad, sino que es parte fundamental de ella porque crea un vínculo entre los fragmentos dispersos de cada identidad potencial". ${ }^{30} \mathrm{La}$ ficción tiende un puente a la memoria.

Esa aprehensión del pasado de la protagonista se materializa en el capítulo número 46 de la primera parte. "La última" presenta al lector la última carta dirigida a Facundo, escrita en el tiempo actual de la historia, que no es enviada, sino eliminada como bits descartables en la computadora de la protagonista. Allí se narra en tercera persona el encuentro sexual entre una mujer, bautizada por su amante como Xenia, a quien Facundo podría identificar con la protagonista debido a la ya abandonada tradición epistolar. De los efectos de la narración impersonal en el relato de su falseada experiencia se percata la protagonista misma:

En una segunda vuelta de tuerca percibe el distanciamiento logrado por el uso de la tercera persona. Yo soy otra, como se ha dicho. Ya no pongo más mi cuerpo en juego, ya no estoy toda yo derramándome en el papel como una erupción de lava. Caliente yo, descontrolada [...] Con F se jugó entera porque de eso se trataba, y brindó lo poco que tenía para brindar: su cuerpo. ${ }^{31}$

Ella ha prestado su cuerpo a la ficción, ha construido un personaje, le ha dado otro nombre y le ha insuflado su deseo. Esta escena aparece en la narración en una especie de mise en abyme, un juego especular entre la novela y la carta que resalta las estrategias de Valenzuela para figurar y desfigurar el yo autobiográfico. La carta, como la novela, muestra la capacidad del sujeto de narrarse otro, de dejarse tomar por la ficción y de sacar de esta una idea de sí mismo. Como con las máscaras que la protagonista colecciona y pone sobre los rostros de sus amigos, la narración la reviste de alteridad y de la capacidad de enfrentar su propia memoria.

28 Valenzuela, La travesía, 106.

29 Ricoeur, Sí mismo como otro, 149.

30 Susana Arroyo Redondo, "La autoficción: Entre la autobiografía y el ensayo biográfico. Límites del género" (tesis de maestría, Universidad de Alcalá, 2011), 147.

31 Valenzuela, La travesía, 293. Énfasis míos. 
La dimensión especular de la voz narrativa, que es otra, pero intenta configurar un yo, y que en la novela aparece en un doble nivel: la de la narradora y la de la protagonista, trae a cuenta los márgenes movedizos de la identidad; esa suerte de consciencia nómade de Rosi Braidotti que libera al sujeto de una visión binaria de la realidad. Lo nómade destruye la estabilidad de todos los márgenes, ${ }^{32}$ incluso aquellos de la primera persona como irrefutable autoridad de las formas de la memoria, centralizada y unívoca, que Valenzuela asocia con la escritura masculina. Para Medeiros-Lichem, la consciencia nómade que deviene de la escritura de la última carta libera a la protagonista de las estructuras monolíticas que la oprimen en lo privado (el hombre al que escribe las cartas) y en lo público (la dictadura). ${ }^{33}$ Después de recuperar las cartas en el último capítulo de la novela, la protagonista revela su nombre, el de su exmarido y el deseo de volver a Argentina, esto es, enuncia su encuentro con la memoria.

La revelación del nombre, que no es el de Luisa Valenzuela, se da en un monólogo de la protagonista que desplaza la narración heterodiegética. Ese movimiento subrepticio del yo aparece insospechadamente en la narración en tercera persona y fragmenta el control sobre la presentación de los hechos que, en las lecturas más convencionales, se espera para la novela (en su narración impersonal) y para la autobiografía (en su narración personal). La tensión que se crea entre esos dos planos diegéticos permite a la autora situarse lejos de las dos antípodas de ambos géneros narrativos.

Pero no es solo allí donde aparece un yo. También la narración de los otros, quienes acompañan a la protagonista, en las cartas o en la autobiografía apócrifa, le sirven de recipiente. A lo largo de La travesía, la narración se despliega en digresiones propias del género ensayístico que suscita el relato de las vidas de otros personajes y en el que suele perderse la historia de la protagonista. Esto se ve desde la botadura, en que la narración de su vida es desplazada por una historia aparentemente mucho más emocionante: la preparación del encuentro entre su amiga Ava, dominatriz de profesión, y un potencial cliente. Este desplazamiento del objeto de la autobiografía aparece, pues, desde las primeras páginas. La protagonista asiste a una historia que, en ocasiones, la supera y en la que se presenta como una transeúnte.

Que la narración de la vida se constituya en una narración sobre los otros no es una cuestión exclusiva de La travesía. Para Arfuch, lo autobiográfico construye, también, una mirada sobre los otros, una demostración de que la vida es inseparable de otras vidas. ${ }^{34}$ Como menciona la autora, ya Bajtín había discurrido sobre la reflexión de la alteridad que se advierte en los géneros biográficos. Según el autor ruso, el desdoblamiento de sí que ocurre en este tipo de obras equipara al biógrafo y al autobiógrafo, debido a que en ambos hay un abandono del yo para construir al otro. El biógrafo se sumerge en el otro para construir un personaje y el autobiógrafo, en busca de objetividad, sale de sí para verse con los ojos de otro. ${ }^{35}$ Esa escritura de la vida de los demás, cuando de escribir la propia vida se trata, aparece en $L a$ travesía como vehículo del pensamiento de Valenzuela sobre la memoria y la violencia.

32 Rosi Braidotti, Sujetos nómades: Corporización y diferencia sexual en la teoría feminista contemporánea (Buenos Aires: Paidós, 2000), 61.

33 Medeiros-Lichem, "El sujeto nómada y la exploración de la memoria en 'La travesía' de Luisa Valenzuela”.

34 Leonor Arfuch, Memoria y autobiografía: Exploraciones en los límites (Buenos Aires: Fondo de Cultura Económica, 2013), 52.

35 Arfuch, Memoria y autobiografía, 49. 
El descentramiento de la narración propia por la de los otros ha sido también estudiada por Julia Negrete Sandoval como configuradora de la literatura latinoamericana de la segunda mitad del siglo XX. Para esta, hay un reemplazo de la potencia de la figura del autor con la aparición de voces cada vez más colectivas, ${ }^{36}$ respondiendo a lo que Fredric Jameson denomina "un nuevo espacio colectivo entre sujetos conocidos y seres humanos individuales", que no se refiere a la pérdida del nombre, sino a su multiplicación. ${ }^{37}$ Asimismo, Negrete Sandoval reconoce el papel de obras autoficcionales y de otras experimentaciones con las narrativas del yo que, por su carácter heterogéneo, permiten a los autores esbozar la complejidad de narrar desde un yo fragmentado, así como la de representar realidades tan desbordantes como la de la dictadura. ${ }^{38}$

La literatura tiene, además, la importante posibilidad de revestir la narración de una experiencia común, con la que cualquiera pueda sentirse interpelado. ${ }^{39}$ Contrario a lo que podría pensarse, la complejidad de los mecanismos narrativos del tipo de obras que señala Negrete Sandoval, más que blindar la identificación con la realidad, crea un sentido amplio en que caben otros referentes. ${ }^{40}$ Sin el yugo del nombre propio, cualquiera puede leerse protagonista.

La dimensión dialógica de la literatura latinoamericana que se ha sabido parte de la construcción de la memoria refleja la existencia paradojal de la esfera de la intimidad anunciada por Nora Catelli. No es posible evitar la invasión del espacio público en la narración de lo privado, y viceversa, si lo que conforma la identidad de manera tan potente es algo que compromete a una nación entera. ${ }^{41}$

Por otro lado, esos mecanismos de desautorización de un yo inalienable mediados por la escritura femenina de Valenzuela dan cuenta de una tradición autobiográfica de mujeres que, no necesariamente valiéndose de las mismas estrategias narrativas, buscan hacer de la voz propia una colectiva. Para Yanbing Er, el feminismo reconcilia el imperativo comunicativo de la autobiografía con una preocupación por la situación de la mujer, se distancia de otras formas autobiográficas producidas por hombres y reemplaza la pretensión ejemplarizante de lo autobiográfico por lo compartido. ${ }^{42}$

Además, Er ha argumentado que, en el caso de las autoficciones, la construcción de propuestas estéticas complejas que reflexionan sobre el lenguaje, la representación y el género permite a las escritoras desafiar la frecuente lectura de la crítica, que no se detiene lo suficiente en el carácter literario de sus obras y las cataloga únicamente bajo la raída etiqueta de sobreexposición del espacio privado. ${ }^{43}$

En La travesía, la presencia de esa multiplicidad de voces se conjura en el carácter ambiguo del pronombre y la desautorización de la primera persona como único garante de un registro auténtico. El

36 Julia Érika Negrete Sandoval, “Tradición autobiográfica y autoficción en la literatura hispanoamericana contemporánea”, Raíz Diversa 2, no. 3 (2015): 235.

37 Negrete Sandoval, “Tradición autobiográfica y autoficción en la literatura hispanoamericana contemporánea”, 235.

38 Negrete Sandoval, “Tradición autobiográfica y autoficción en la literatura hispanoamericana contemporánea”, 226.

39 Richard, Fracturas de la memoria, 49.

40 Richard, Fracturas de la memoria, 49.

41 Nora Catelli, En la era de la intimidad: Seguida de El espacio autobiográfico (Buenos Aires: Beatriz Viterbo, 2007$), 15$.

42 Yanbing Er, "Contemporary Women's Autofiction as Critique of Postfeminist Discourse”, Australian Feminist Studies 33, no. 97 (2018): 316.

43 Er, “Contemporary Women's Autofiction as Critique of Postfeminist Discourse”, 318. 
descentramiento de la voz abre la pluralidad de puntos de vista. Esa urdiembre de interlocución posibilita una relación especular entre quien lee y quien es narrado.

Aunque Valenzuela ha manifestado su reticencia hacia la escritura biográfica, ${ }^{44}$ probablemente huyendo, como muchas otras escritoras, del empeño de la crítica en leer en cada pieza narrativa un intento de autobiografía, eso no impidió la creación de una obra como La travesía, que no solo atiende de manera completa al valor biográfico señalado por Bajtín, sino que reflexiona cabalmente sobre las posibilidades de la enunciación de la propia memoria y la configuración de la identidad desde la ficción. En La travesía, Valenzuela es autobiógrafa y biógrafa de otra que no es ella.

Como ha querido mostrarse a lo largo de este artículo, La travesía es manifiesto del complejo estético de Valenzuela que no necesita valerse de retratos exactos de la historia argentina para denunciar el horror. Si los temas de dictadura y opresión de género resuenan, en ocasiones vagamente, entre su agudo humor, la estructura de la novela y sus estrategias narrativas no pueden dejar de decir que es un sujeto escindido el que intenta narrar la memoria desmembrada de la violencia. La parodización, la ironía y la creación de escenarios caprichosos responden a una realidad que se mueve entre absurdos. Ante esa, Valenzuela propone una escritura femenina que con el cuerpo se ancla en el mundo y que brama que no es posible ya comprenderse desde una estructura patriarcal, militar y autorial. Ese bramido, como la voz de la protagonista de la novela, a veces es coral y a veces un desencuentro. En ningún caso, es la voz de un yo unívoco que pretende agotar su experiencia en la narración.

\section{Bibliografía}

Arfuch, Leonor. El espacio biográfico: Dilemas de la subjetividad contemporánea. Buenos Aires: Fondo de Cultura Económica, 2002.

Arfuch, Leonor. Memoria y autobiografía: Exploraciones en los límites. Buenos Aires: Fondo de Cultura Económica, 2013.

Arroyo Redondo, Susana. "La autoficción: Entre la autobiografía y el ensayo biográfico. Límites del género". Tesis de maestría, Universidad de Alcalá, 2011.

Benveniste, Émile. Problemas de lingüística general. México: Siglo XXI, 1979.

Braidotti, Rosi. Sujetos nómades: Corporización y diferencia sexual en la teoría feminista contemporánea. Buenos Aires: Paidós, 2000.

Bürger, Peter y Christa Bürger. La desaparición del sujeto: Una historia de la subjetividad de Montaigne a Blanchot. Madrid: Akal, 2001.

Camarero, Jesús. Autobiografía: Escritura y existencia. Barcelona: Anthropos, 2011.

Catelli, Nora. En la era de la intimidad: Seguida de El espacio autobiográfico. Buenos Aires: Beatriz Viterbo, 2007.

Cook, Alyce. "Luisa Valenzuela's La travesía: A Search for Order". En Modernisms and Modernities: Studies in Honor of Donald L. Shaw, editado por Susan Carvalho, 321-331. Newark: Juan de la Cuesta, 2006.

Couture-Grondin, Élise. "La expresión del deseo en la literatura femenina como respuesta a la opresión dictatorial y patriarcal en la obra de Luisa Valenzuela”. Tesis de maestría, Université de Montréal, 2011.

Díaz, Gwendolyn. "Una odisea hacia el caos: 'La travesía' de Luisa Valenzuela”. Biblioteca Virtual Miguel de Cervantes. http://www.cervantesvirtual.com/obra/una-odisea-hacia-el-caos-la-travesia-de-luisa-valenzuela-931424/.

44 Valenzuela, Escritura y secreto, 92. 
Er, Yanbing. "Contemporary Women's Autofiction as Critique of Postfeminist Discourse". Australian Feminist Studies 33, no. 97 (2018): 316-330. https://doi.org/10.1080/08164649.2018.1536442

Gómez, Jaime P. "La representación de la dictadura en la narrativa de Marta Traba, Isabel Allende, DiamelaEltit y Luisa Valenzuela”. Confluencias 12, no. 2 (1997): 89-99.

González Sawczuk, Susana Ynés. "A dos tiempos: Narrativas de autoficción en La travesía de Luisa Valenzuela”. En Luisa Valenzuela: Perspectivas críticas. Ensayos inéditos, coordinado por Pol Popovic-Karic y Fidel Chávez, 3962. Monterrey: Instituto Tecnológico y de Estudios Superiores de Monterrey, 2013.

Lejeune, Philippe. El pacto autobiográfico y otros estudios. Madrid: Megazul Endymion, 1994.

Logan, Joy. "Southern Discomfort in Argentina: Postmodernism, Feminism, and Luisa Valenzuela's 'Simetrías"'. Latin American Literary Review 24, no. 48 (1996): 5-18.

Martínez, Nelly. "Luisa Valenzuela’s 'La travesía': The Vagina Monologues and the Experience of Wholeness". Letras Femeninas 30, no. 1 (2004): 92-105.

Medeiros-Lichem, María Teresa. "El sujeto nómada y la exploración de la memoria en 'La travesía' de Luisa Valenzuela". Biblioteca Virtual Miguel de Cervantes. http://www.cervantesvirtual.com/obra/el-sujeto-nomaday-la-exploracion-de-la-memoria-en-la-travesia-de-luisa-valenzuela-931776/.

Medeiros-Lichem, María Teresa. "Luisa Valenzuela: 'La mala palabra". La voz femenina en la narrativa latinoamericana: Una relectura crítica, 199-231. Santiago de Chile: Cuarto Propio, 2006.

Medeiros-Lichem, María Teresa. "Nuevos derroteros del lenguaje: La travesía de la escritura de Luisa Valenzuela". Biblioteca Virtual Miguel de Cervantes. http://www.cervantesvirtual.com/obra/nuevos-derroteros-del-lenguajela-travesia-de-la-escritura-de-luisa-valenzuela-931752/.

Negrete Sandoval, Julia Érika. "Tradición autobiográfica y autoficción en la literatura hispanoamericana contemporánea”. Raíz Diversa 2, no. 3 (2015): 221-242. https://doi.org/10.22201/ppela.24487988e.2015.3.58594

Piña, Cristina. "La narrativa argentina de los años setenta y ochenta". Cuadernos Hispanoamericanos, no. 517-519 (1993): 121-138.

Richard, Nelly. Fracturas de la memoria. Buenos Aires: Siglo XXI, 2004.

Ricoeur, Paul. Sí mismo como otro. Madrid: Siglo XXI, 2013.

Rousseau, Jean-Jacques. Las confesiones. Madrid: Edaf, 1980.

Sarlo, Beatriz. Tiempo pasado: Cultura de la memoria y giro subjetivo. Una discusión. Buenos Aires: Siglo XXI, 2011.

Scarano, Laura. Palabras en el cuerpo: Literatura y experiencia. Buenos Aires: Biblos, 2007.

Selimović, Ilena. "Sexing of the City: Desire, Memory, and Trauma in Luisa Valenzuela's La travesía". Revista Hispánica Moderna 60, no. 2 (2017): 205-219. https://doi.org/10.1353/rhm.2007.0010

Swanson, Philip. "The Post-boom Novel". En The Cambridge Companion to the Latin American Novel, editado por Efraín Kristal, 81-105. Cambridge: Cambridge University Press, 2005. https://doi.org/10.1017/ CCOL0521825334.005

Valenzuela, Luisa. Escritura y secreto. México: Ariel, 2002.

Valenzuela, Luisa. La travesía. México: Alfaguara, 2002. 